\title{
Does habitat loss affect tropical myxomycetes?
}

\author{
Rojas $\mathbf{C}^{1,2}$ and Doss $\mathbf{R G}^{3}$ \\ ${ }^{1}$ Forest Resources Unit, Engineering Research Institute, University of Costa Rica, 11501 -Costa Rica \\ ${ }^{2}$ Department of Biosystems Engineering, University of Costa Rica, 11501-Costa Rica \\ ${ }^{3}$ Apdo. 186-3100, Santo Domingo de Heredia, 40306-Costa Rica.
}

Rojas C, Doss RG 2014 - Does habitat loss affect tropical myxomycetes? Mycosphere 5(5), 692700, Doi 10.5943/mycosphere/5/5/11

\begin{abstract}
The effect of habitat loss on the dynamics of myxomycete assemblages has been poorly studied thus far. For this reason, a premontane moist forest surrounded by human-created pastures on the Caribbean slope of Costa Rica was selected to carry out a pilot ecological evaluation using a systematic approach. In the area of study, a series of forest zones representing a gradual continuum of habitat variation was selected and characterized using structural forest parameters. Fruiting bodies of myxomycetes were surveyed across these zones and microhabitat variables were measured when fruiting bodies were found. Results indicated that species richness, species diversity and the number of unique species recorded as fruiting bodies increased linearly from areas without suitable habitat to areas with complete suitable habitats and such pattern was shown to be correlated with canopy openness. Since the latter factor is clearly dissimilar across areas with structural differences in the forest being studied, the results presented herein suggest that myxomycetes are affected by the modification and loss of suitable habitats.
\end{abstract}

Key words - border effect - forest fragmentation - myxogastrids - Neotropics - rainforest dynamics.

\section{Introduction}

During the past few years, there have been a number of studies of different aspects of myxomycete ecology (e.g., Ko Ko et al. 2011, Takahashi 2013, Clayton et al. 2014). Even though most of these studies are largely descriptive in nature (i.e., Goad \& Stephenson 2013), they have documented a series of ecological relationships between the reproductive stage of myxomycetes and environmental characteristics associated with different types of ecosystems. As a result of carrying out the studies, researchers have found that species assemblages of myxomycetes vary, even within an ecosystem type, depending on the particular combination of external factors shaping the particular more limited biosystem in which they occur.

Even though such a general model for myxomycetes may be the result of a fine equilibrium between ecological and evolutionary controls (Rojas \& Valverde 2014), published data clearly show that different assemblages exist, depending on the geographical location, macroclimatic characteristics and biosystem type. In this manner, researchers have known for some time that for a particular forest type and location there seems to be a defining group of core species and another group of incidental taxa that vary from place to place (see Schnittler and Stephenson 2000). Whether or not these results would hold up to scientific testing really depends on the use of 
appropriate future approaches to confirm or refute the hypothesis mentioned above. However, as an operational idea from which to work, it seems to be logical and supported by empirical data.

In this way, it would be consistent with the direction of both myxomycete and tropical forest research to evaluate the relationship between system quality and the occurrence of these microorganisms. Since the effects of habitat loss and forest fragmentation are largely undocumented in tropical areas (Bhagwat 2014) and myxomycetes may represent an especially good taxonomic group for structural dynamics research (see Rojas \& Stephenson 2013), a combined approach seems adequate for the development of integrated studies. The latter is particularly significant when it is considered that changes in habitat quality have an impact on biodiversity conservation (Hill et al. 2011).

Habitat loss probably has a stronger impact on species assemblages than forest fragmentation itself (Fahrig 2003). However, there is still little known about the dynamics of the effect of habitat loss on the majority of organisms (Swift \& Hannon 2009). Since the latter applies to myxomycetes, the study presented herein has been designed with the main objective of documenting the effect of habitat variation on myxomycete assemblages through a border effectbased approach. Even though this investigation has been conceived as a pilot study for future research, it also was designed to provide additional ecological information on tropical myxomycetes.

\section{Materials \& Methods}

This study was carried out during May 2011 in Buenos Aires de Guápiles in the Caribbean region of Costa Rica. The study area was the Albergue Centro Manú (hereafter referred to as Manu), an educational/research facility located in the premontane region of the northern slope of the Turrialba volcano. This area is located between 10.1571-10.1587 N latitude and 83.7762$83.7839 \mathrm{~W}$ longitude, approximately at $535 \mathrm{~m}$ above sea level. With a precipitation regime of about $4500 \mathrm{~mm}$ of rain per year and an average temperature of $21^{\circ} \mathrm{C}$, the forests of Manu are defined as Premontane Tropical Moist Forests according to the Holdridge classification (Holdridge et al. 1971).

For this study, only lignicolous and litter-inhabiting myxomycetes recorded directly in the field were considered. As such, forested areas were treated as suitable habitats and totally or partially intervening areas were treated as experimental ones. The reason for the latter resides in the fact that lignocellulosic substrates, always present in forests, are usually associated with the fruiting bodies of myxomycetes. The morphological concept of species was used, and the nomenclature followed herein is that of Lado (2005-2014). The genus Ceratiomyxa also was included due its ecological equivalence to the true myxomycetes. All specimens collected were deposited in the herbarium of the University of Costa Rica (USJ).

\section{Study area selection}

Manu is part of a 150 ha forest patch bordering a pasture in the buffer area of the Guácimo-Pococí Aquifer Protected Zone. As such, it is located in the transitional zone between protected and human-intervened areas. This area was selected during the present study as suitable for the hypothesis to be tested for two reasons. The first is that a clear straight edge on one section of the border between the forest and the pasture created the presence of a sharp ecotone with homogenous vegetation on either side (Fig. 1A). The second reason is that functional differences in vegetation structure on either side of the border were found to exist, according to the Normalized Difference Vegetation Index (NDVI) calculated using Landsat 7 imagery from March 2011, thus providing support to the idea that the site was suitable for structural characterization (Fig. 1B).

\section{Experimental design and data collection}

Four south-north transects were established perpendicular to the sharp ecotone between forested and non-forested patches in the study area and placed $100 \mathrm{~m}$ from each other. Along each transect, four circular $10 \mathrm{~m}$ radius study points were established every $50 \mathrm{~m}$. Two of these study 
points were located inside habitat zones defined by the forest (recognized herein as internal and external habitats), one in a habitat zone determined by the forest border (transitional habitat) and one in a habitat zone determined by the non-forested section of the pasture (no suitable habitat, see Fig. 2). In this way, the total area sampled for each habitat zone equaled 1256.64 square meters or about 0.13 hectares. Georeferencing of all study sites was carried out by obtaining a GPS reading in the field and correcting the position using an orthorectified image of the study area and commercially available GIS data.

Four parameters for the characterization of forest structure were taken at each study point. The variables measured or determined were temperature, relative humidity, canopy openness and Leaf Area Index (LAI). The first two were recorded every 15 min for seven days previous to field surveys with HOBO Pro Series dataloggers. For the last two, hemispherical pictures were taken in the field during May 2011 and post-processed using the Gap Light Analyzer (Frazer et al 1999). In addition to the latter, some substructural parameters also were determined. For this, the estimated number of sunflecks shorter than 4 min reaching the understory, the total transmitted radiation (in mols per square meter per day) as well as the gap fraction (ratio of sky pixels to total pixels per sky-region segment) and percentage of total transmitted light (watts per square meter) at 35 degrees from the zenith also were calculated by establishing the trajectory of the sun for the study area.

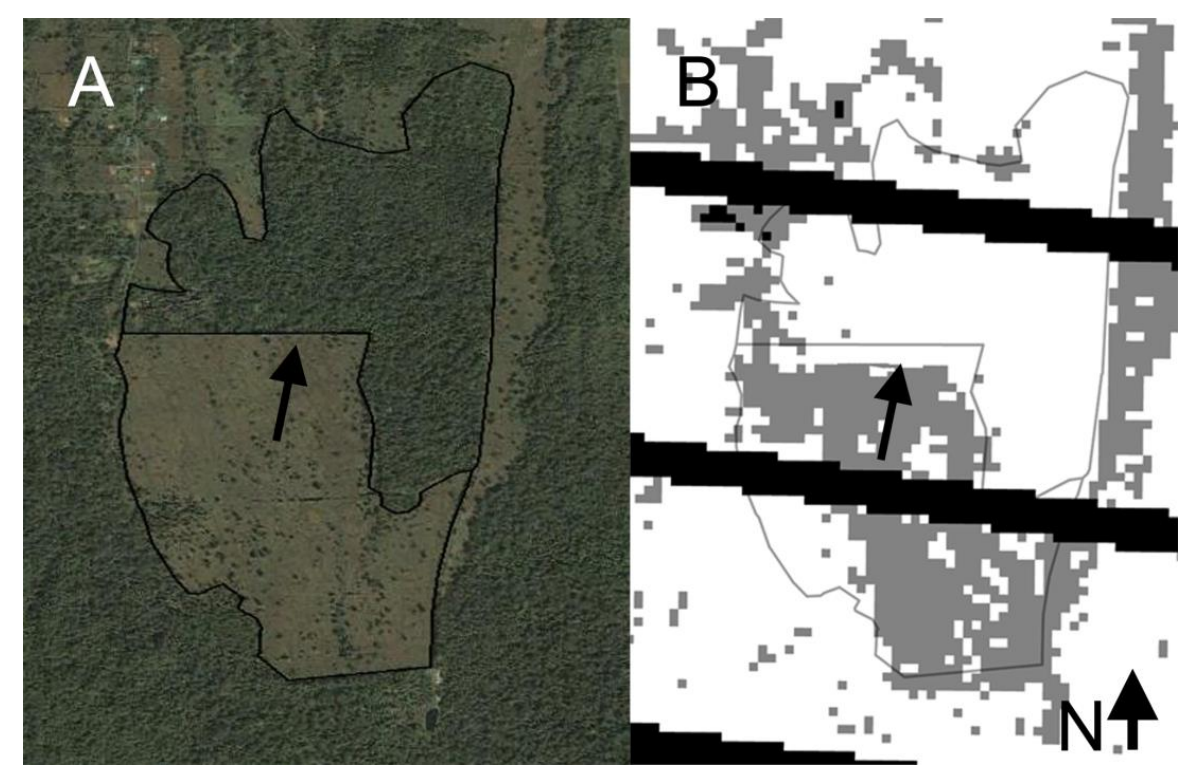

Fig. 1 - Satellite imagery showing the characteristics of the area under study. A) Natural color image and B) highly simplified NDVI-based diagram. In both cases, the area covered by the forested and non-forested patches studied is shown and the forest border studied is marked with an arrow. NDVI values oscillated between $0.37-0.68$ for the forest (white) and between $0.24-0.34$ for the pasture (gray). The black strips are due to the failure of the scan line corrector in the ETM+ module of Landsat 7.

Myxomycetes were carefully surveyed by a team of seven people for 40 minutes at each study point. All of these sampling points were revisited and surveyed with the same sampling effort three days after first survey in order to record any possible missing records missed during the initial survey. All collections were curated in the manner described by Stephenson and Stempen (1994). For each record, a series of microenvironmental variables was determined in situ. Among the latter, the diameter of the decayed log or twig, the height above the ground and the stage of decay of the substrate were considered. The first two were determined with a measuring tape and the third one was obtained by using the protocol of Hunter (1990), based on the recommendation of Larjavaara \& Muller-Landau (2010) for quick field assessments. Finally, the average length of the stalk, calculated from a ten stalk measurement for all stalked forms, also was obtained as a functional parameter to evaluate the environmental influence on the fructification process. 


\section{Data Analysis}

A species accumulation curve was generated for the complete dataset and corrected with the formula $y=a x /(b+x)$. With this approach, the parameter $a$ is equivalent to the maximum number of species to be encountered with the intensity and characteristics of the methodology used. In this way, the effectiveness of the survey was calculated by using $a$ as a proxy for total species richness.

Differences in values for all parameters measured were evaluated using the Kruskal-Wallis test after calculating the average of the parameters for each habitat zone from the data collected at each individual study point. In addition, a Principal Component Analysis (PCA) was carried out using all the structural and substructural parameters obtained. After analyzing general patterns in the variation of the dataset, correlations among species richness and species diversity (using the Shannon-Wiener Index) with principal components were carried out using the Spearman's Rho non parametric estimator. When direction of differences was evaluated, a Tukey test was performed.

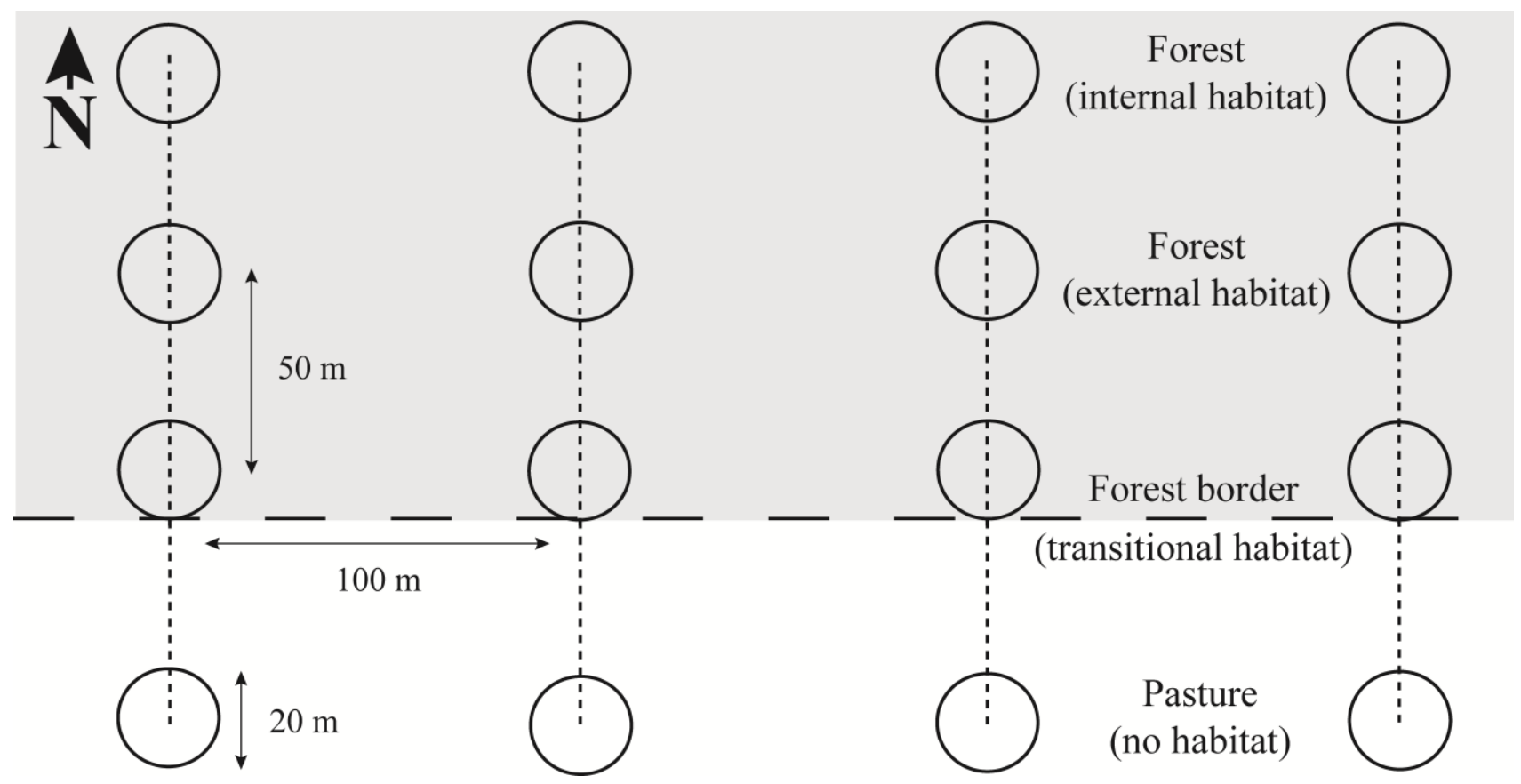

Fig. 2 - Border effect-based spatial design used for the collection of data during the present study. For survey intensity, see the Material and Methods section.

\section{Results}

A total of 291 myxomycetes classified in 28 species and 11 genera were recorded during the present investigation (Table 1). For the effort set during this study, approximately two myxomycetes per minute or one every $69 \mathrm{~m}^{2}$ of surveyed area were found. A species accumulation curve generated for the overall dataset indicated that this effort was enough to recover approximately $67 \%$ of the species with the protocol used (Fig. 3). The most common recorded species were Ceratiomyxa fruticulosa, Hemitrichia calyculata and Arcyria cinerea, with approximately $24 \%$ of all myxomycetes represented by the first two and $18 \%$ for the last one.

Significant variations in the structural parameters were found for the three major types of habitats considered in the study (see Table 2). Interestingly, differences also were found when microenvironmental parameters were considered, except for stage of decay, which remained consistent throughout the habitat continuum. Even the only functional parameter recorded, stalk length, showed significant differences across the study zones. For the structural variables, the tendency indicated that temperature and atmospheric moisture varied between the pasture and the other zones, with little variation inside the forest. However, canopy openness, gap fraction, total transmitted light and transmitted radiation decreased gradually from the non-habitat to the habitat zones. As expected, LAI increased along the same gradient. 
Table 1 Number of records of myxomycetes collected during the present study, arranged by species and habitat zones.

\begin{tabular}{|c|c|c|c|c|}
\hline \multirow[t]{2}{*}{ Species } & \multicolumn{4}{|c|}{ Habitat zones } \\
\hline & $\begin{array}{l}\text { No } \\
\text { habitat }\end{array}$ & $\begin{array}{l}\text { Transitional } \\
\text { habitat }\end{array}$ & $\begin{array}{l}\text { External } \\
\text { habitat }\end{array}$ & $\begin{array}{l}\text { Internal } \\
\text { habitat }\end{array}$ \\
\hline Arcyria cinerea (Bull.) Pers. & 4 & 11 & 19 & 20 \\
\hline Arcyria denudata (L.) Wettst. & & 1 & 3 & 11 \\
\hline Arcyria magna $\operatorname{Rex}$ & & 1 & & \\
\hline Ceratiomyxa fruticulosa (O.F. Müll.) T. Macbr. & & 26 & 16 & 30 \\
\hline Ceratiomyxa sphaerosperma Boedijn & & & & 3 \\
\hline Comatricha pulchella (C. Bab.) Rostaf. & & & 1 & \\
\hline Cribraria cancellata (Batsch) Nann.-Bremek. & & 3 & & \\
\hline Cribraria intricata Schrad. & 1 & & 2 & 2 \\
\hline Cribraria languescens $\mathrm{Rex}$ & & & 1 & \\
\hline Cribraria splendens (Schrad.) Pers. & & 1 & 2 & \\
\hline Cribraria tenella Schrad. & & 3 & 1 & \\
\hline Diachea bulbillosa (Berk. \& Broome) Lister & & 1 & & \\
\hline Didymium clavus (Alb. \& Schwein.) Rabenh. & & & & 1 \\
\hline Didymium nigripes (Link) Fr. & 1 & & 2 & 2 \\
\hline Hemitrichia calyculata (Speg.) M.L. Farr & 4 & 14 & 15 & 38 \\
\hline Lycogala epidendrum (L.) Fr. & 3 & & 5 & 3 \\
\hline Physarum compressum Alb. \& Schwein. & & & & 1 \\
\hline Physarum didermoides (Pers.) Rostaf. & & & & 1 \\
\hline Physarum melleum (Berk. \& Broome) Massee & & & 1 & \\
\hline Physarum polycephalum Schwein. & & & & 1 \\
\hline Physarum stellatum (Massee) G.W. Martin & & & & 2 \\
\hline Physarum viride (Bull.) Pers. & & & & 1 \\
\hline Stemonitis axifera (Bull.) T. Macbr. & & 5 & 3 & 5 \\
\hline Stemonitis fusca Roth & 2 & 3 & 4 & 3 \\
\hline $\begin{array}{l}\text { Stemonitopsis typhina (F.H. Wigg.) Nann.- } \\
\text { Bremek. }\end{array}$ & & & & 2 \\
\hline Trichia favoginea (Batsch) Pers. & 1 & & & \\
\hline Trichia varia (Pers. ex J.F. Gmel.) Pers. & & 1 & & \\
\hline $\begin{array}{l}\text { Tubifera microsperma (Berk. \& M.A. Curtis) } \\
\text { G.W. Martin }\end{array}$ & & & 3 & \\
\hline Number of unique species & 1 & 5 & 6 & 8 \\
\hline Total & 16 & 70 & 78 & 126 \\
\hline
\end{tabular}

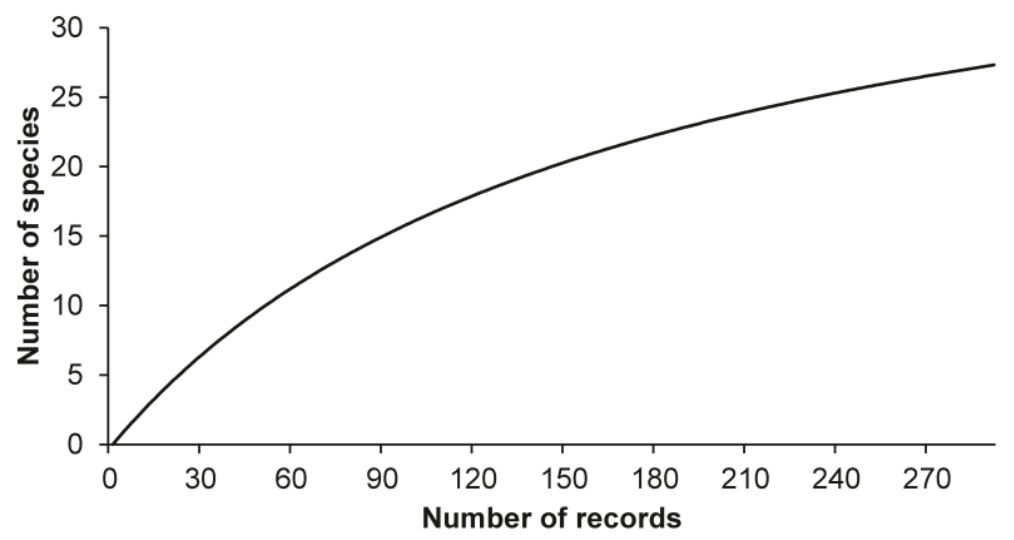

Fig. 3 - Species accumulation curve constructed with the overall dataset of records obtained during the present study. The maximum number of species was calculated as 42 . 
The PCA analysis showed that approximately $97 \%$ of structural variation in the dataset for the different study zones was explained by canopy openness alone. When species richness, abundance and diversity values were analyzed according to that parameter, highly significant negative correlations were observed for all combinations ( $\rho=-0.92,-0.87$ and -0.74 , respectively). A similar pattern was observed for temperature and atmospheric moisture. Interestingly, the number of unique species also showed a high negative correlation with canopy openness $(\rho=-0.93)$. Since substrate availability is one of the factors determining the presence of habitats for myxomycetes, a comparison of substrate types across the study zones was carried out, but no differences were found. However, height above the ground was found to be significantly higher in the no habitat zone (Tukey $P<0.05$ for all comparisons).

It is interesting to note that among the species recorded in the no habitat zone, there were four different orders of myxomycetes represented. Even though the same result was found for all other zones, it was also clear that species of the genera Physarum, Ceratiomyxa and Cribraria were associated with habitat zones. At the same time, it seemed that the abundance of Hemitrichia calyculata was the only variable showing a moderate correlation with a structural parameter $(\rho=-$ 0.68 for canopy openness). Even though the length of the stalk showed overall differences between the no habitat and habitat zones, this difference disappeared when the two most common stalked species, Hemitrichia calyculata and Arcyria cinerea, were evaluated individually.

\section{Discussion}

The present study was conceived as a preliminary assessment of the effect of habitat variation on myxomycetes. In this manner, results should be carefully interpreted, since they correspond to the particular system and conditions studied. In spite of that fact, this study provides interesting data to strengthen the theoretical framework for future ecological studies on tropical myxomycetes.

The completeness of the survey has been similar to other rapid assessment projects in tropical areas using either field collections (e.g., Stephenson et al. 2004) or collections from moist chamber cultures (Schnittler \& Stephenson 2000). In this way, the survey carried out for this study is probably as representative as it could be using the methodology and effort described above. Similarly, the recorded species assemblage resembles in large degree, other previously observed premontane tropical moist forest communities from Costa Rica (see Rojas et al. 2010). In this way, none of the records was surprising from a distributional perspective. Therefore, the assemblage has been considered representative of the studied area.

Most of the structural changes in the forest are somehow intuitive. However, the quantification of parameters is valuable for future research on ecosystem-based microbial ecology, since comparative analyses can be carried out with further detail once baseline data are in place. In this sense, given the fact that this study was set up on the conceptual basis that forested areas represented a "habitat zone" for myxomycetes, it should be noted that any negative effect on the occurrence of particular species should be restricted to the forest-associated assemblages. As such, it was interesting to observe that even with little structural and microenvironmental variation within the forest, there were significant differences in species richness, diversity and number of unique species inside of the forest.

Experienced myxomycete researchers recognize the presence of "fruiting body hotspots" within particular biological systems, but the underlying basis of such a pattern is still not well understood. Even though the results presented herein are limited in both space and time, they seem to suggest that these hotspots are regulated, among other factors, by structural characteristics of the forest. The latter indirectly determines the quality and quantity of potential microhabitats on which fruiting bodies can occur. In this way, their occurrence is dependent on more than just substrate quality parameters such as $\mathrm{pH}$, stage of decay and substrate type that influence the development of myxomycete fruiting bodies. However, whether or not species distribution based solely on fruiting body data is truly representative is not yet known and will depend upon the data obtained from future research incorporating molecular approaches as well. 
Table 2 Average values for the parameters considered during the present investigation according to habitat zones and probability results from the hypothesis testing evaluation.

\begin{tabular}{|c|c|c|c|c|c|}
\hline \multirow[t]{2}{*}{ Parameter } & \multicolumn{4}{|c|}{ Habitat zones } & \multirow{2}{*}{$\begin{array}{l}\text { Probability of no } \\
\text { difference across } \\
\text { hábitat zones }\end{array}$} \\
\hline & $\begin{array}{c}\text { No } \\
\text { habitat }\end{array}$ & $\begin{array}{c}\text { Transitional } \\
\text { habitat }\end{array}$ & $\begin{array}{c}\text { External } \\
\text { habitat }\end{array}$ & $\begin{array}{l}\text { Internal } \\
\text { habitat }\end{array}$ & \\
\hline \multicolumn{6}{|l|}{ Structural } \\
\hline Temperature $\left({ }^{\circ} \mathrm{C}\right)$ & 23.4 & 20.6 & 20.7 & 20.5 & 0.001 \\
\hline Atmospheric moisture (\%) & 87.3 & 94.2 & 96.8 & 96.3 & 0.001 \\
\hline Canopy openness (\%) & 93.5 & 17 & 11 & 8.3 & 0.001 \\
\hline Leaf Area Index & 0.05 & 2.19 & 2.93 & 2.92 & 0.001 \\
\hline \multicolumn{6}{|l|}{ Substructural } \\
\hline Sunflecks $<4$ min & 132 & 3956 & 2841 & 2697 & 0.001 \\
\hline Gap fraction & 0.95 & 0.18 & 0.15 & 0.12 & 0.001 \\
\hline $\begin{array}{l}\text { Total transmitted light } \\
\left(\mathrm{mol} / \mathrm{m}^{2} \mathrm{~d}\right)\end{array}$ & 7.74 & 1.3 & 0.97 & 0.97 & 0.001 \\
\hline $\begin{array}{l}\text { Transmitted radiation } \\
\left(\mathrm{W} / \mathrm{m}^{2}\right)\end{array}$ & 96.4 & 16.6 & 13.6 & 10.1 & 0.001 \\
\hline \multicolumn{6}{|l|}{ Microenvironmental } \\
\hline Decay stage (1-5 scale) & 2.68 & 2.9 & 2.87 & 2.84 & 0.96 \\
\hline Height above ground $(\mathrm{cm})$ & 51.1 & 23.1 & 27.9 & 21.2 & 0.007 \\
\hline Substrate diameter $(\mathrm{cm})$ & 19.7 & 19.4 & 17.8 & 11.4 & 0.003 \\
\hline \multicolumn{6}{|l|}{ Functional } \\
\hline Stalk length (mm) & 0.89 & 1.72 & 1.95 & 1.71 & 0.01 \\
\hline
\end{tabular}

In any case, it is interesting to note that canopy openness was the most important structural component explaining the variation in the studied zones. Although this is not surprising, given the difference that exists between the habitat and the no habitat zones; it was interesting to see that the variation from the forest border into the internal zones was similar to what has been reported in the past for other Central American premontane moist areas (see Williams-Linera 1990). In this way, the usefulness of an a priori remote sensing-based methodology for the selection of the study area seems appropriate for future research on myxomycetes that require a more complex theoretical framework or a systematic experimental model like the one used herein.

Interestingly, during the present study, four orders of myxomycetes were recorded from all habitat zones and the ratio of species to genera (not shown before) ranged between 1.9 and 2.1 for the forested zones. The latter suggests that differences in species assemblages are due largely to the presence of rare species that create the variation in the mentioned ratio. However, the associated abundance of Hemitrichia calyculata with canopy openness also suggests that common species can be affected by a structural parameter, but less strongly than rare ones. Similarly, the lack of differences in stalk length for two common species may indicate that the potential ecological effect of environmental variation on the phenotype is controlled by plasticity. The latter has been partially documented in other ecosystems in Costa Rica as well (Rojas \& Valverde 2014).

In the present study, the strongest negative correlations between canopy openness, as the main determinant of forest structure, and community ecology-based variables were observed for species richness and the number of unique species recorded from each of the studied habitat zones. A similar result was reported by Rojas \& Stephenson (2013) for the lowland Amazon forests of Peru, where the highest species richness and most unique species were recorded for old-growth forest patches, and the lowest values for both indicators were recorded for disturbed areas. What seem noteworthy is that in both of the study mentioned above and the present study, the number of unique species is a function of species richness, with a very stable ratio of 1:0.07. In this way, for 
every 14-15 species detected in the field using classical methodologies, one unique species for the particular biological system under study would be recorded as well.

One direct implication of the last result is that, as has been observed in large-scale studies (e.g., Stephenson et al. 2008), myxomycete data from reproductive structures suggests that diversity patterns are associated with niche-based strategies. In this way, more structurally complex biological systems such as the habitat zones of the present study would be expected to have a higher probability than simpler systems, such as the no habitats zones, of being colonized by a larger number of species due to a higher number of potential niches. In this manner, the effect of habitat variation on the occurrence of fruiting bodies of myxomycetes would be determined by the gradual loss of niches as a product of the structural variation of the system. In this sense, it would be interesting to carry out systematic vertical sampling in tropical forests as well. With that, a more proper evaluation of the effect of structural parameters would be possible.

\section{Acknowledgements}

This study was supported financially by the School for Field Studies through the Centro de Estudios sobre Desarrollo Sostenible in Atenas, Costa Rica. Gratitude is extended to participants in the the 2011 Manú Program for assistance in the field, to Marvin Vargas and Gerardo Avalos for logistic support and to Leonardo Matarrita and Bertlicia Gutiérrez for their help setting up the project. Additional cooperation has been received from the University of Costa Rica though research code 731-B4-072 from the Vicerrectoría de Investigación.

\section{References}

Bhagwat S. 2014 - The history of deforestation and forest fragmentation: a global perspective. In Kettle CJ, Koh LP. (eds) Global Forest Fragmentation. CABI, United Kingdom.

Clayton M, Rollins AW, Stephenson SL. 2014 - Patterns of occurrence of corticolous myxomycetes on white oak trees of two different size classes. Fungal Ecology 7, 9-15.

Fahrig L. 2003 - Effects of habitat fragmentation on biodiversity. Annual Review of Ecology, Evolution, and Systematics 34, 487-515.

Frazer GW, Canham CD, Lertzman KP. 1999 - Gap Light Analyzer. Simon Fraser University, Canada.

Goad AE, Stephenson SL. 2013 - Myxomycetes appearing in moist chamber cultures on four different types of dead leaves. Mycosphere 4, 707-712.

Hill JK, Gray MA, Khen CV, Benedick S, Tawatao N, Hamer KC. 2011 - Ecological impacts of tropical forest fragmentation: how consistent are patterns in species richness and nestedness? Philosophical Transactions of the Royal Society B 366, 3265-3276.

Holdridge LR, Grenke WC, Hatheway WH, Liang T, Tosi JA. 1971 - Forest Environments in Tropical Life Zones: a Pilot Study. Pergamon Press, Oxford.

Hunter ML. 1990 - Wildlife, forests and forestry: principles of managing forests for biological diversity. Prentice Hall, New Jersey.

Ko Ko T, Stephenson SL, Hyde KD, Lumyong S. 2011 - Influence of seasonality on the occurrence of myxomycetes. Chiang Mai Journal of Science 38, 71-84.

Larjavaara M, Muller-Landau HC. 2010 - Comparison of decay classification, knife test, and two penetrometers for estimating wood density of coarse woody debris. Canadian Journal of Forestry Research 40, 2313-2321.

Lado C. 2005-2014 - An on line nomenclatural information system of Eumycetozoa. Real Jardín Botánico de Madrid, Spain. http://www.nomen.eumycetozoa.com (accessed 7 October 2014).

Rojas C, Stephenson SL, Schnittler M. 2010 - A review of the Costa Rican myxomycetes (Amebozoa). Brenesia 73-74, 39-57.

Rojas C, Stephenson SL. 2013 - Effect of forest disturbance on myxomycete assemblages in the southwestern Peruvian Amazon. Fungal Diversity 59, 45-53. 
Rojas C, Valverde R. 2014 - Ecological patterns of lignicolous myxomycetes from two different forest types in Costa Rica. Nova Hedwigia (in press).

Schnittler M, Stephenson SL. 2000 - Myxomycete biodiversity in four different forest types in Costa Rica. Mycologia 92, 626-637.

Stephenson SL, Stempen H. 1994 - Myxomycetes: a handbook of slime molds. Timber Press, Oregon.

Stephenson SL, Schnittler M, Lado C. 2004 - Ecological characterization of a tropical myxomycete assemblage - Maquipucuna Cloud Forest Reserve, Ecuador. Mycologia 96, 488, 497.

Stephenson SL, Schnittler M, Novozhilov Y. 2008 - Myxomycete diversity and distribution from the fossil record to the present. Biodiversity and Conservation 17, 285-301.

Swift TL, Hannon SJ. 2009 - Critical thresholds associated with habitat loss: a review of the concepts, evidence, and applications. Biological Reviews 85, 35-53.

Takahashi K. 2013 - Myxomycete distribution varies among leaf litters of different vegetation in a local secondary forest of warm-temperate western Japan. Mycoscience 54, 368-377.

Williams-Linera G. 1990 - Vegetation structure and environmental conditions of forest edges in Panama. Journal of Ecology 78, 356-373. 